\title{
Redesign do Serious Game Caixa de Pandora para Dispositivos Móveis
}

\author{
Júlio R. Oliveira ${ }^{1,3}$, Zildomar C. Félix ${ }^{3}$, Luana R. Almeida² ${ }^{2}$ Ana Tereza Medeiros ${ }^{3}$, Liliane S. Machado ${ }^{1,3}$ \\ ${ }^{1}$ Departamento de Informática, ${ }^{2}$ Departamento de Enfermagem em Saúde Coletiva, \\ ${ }^{3}$ Laboratório de Tecnologias para o Ensino Virtual e Estatística (LabTEVE) \\ Universidade Federal da Paraíba \\ julio.rapha@hotmail.com, zildomarf@gmail.com, luanaralmeida02@gmail.com, anaterezaprof@gmail.com, \\ liliane@di.ufpb.br
}

Palavras-chave: Serious Games, Caixa de Pandora, Android Apps.

Introdução. Serious Games são jogos que possuem um propósito específico que extrapola a ideia de entreter para oferecer novos tipos de experiência aos seus usuários [1]. Caixa de Pandora é um serious game desenvolvido por Almeida et al. [2] para execução em computadores pessoais, que possui como objetivo a capacitação dos profissionais da área da saúde sobre a violência contra a mulher, por meios de passatempos que foram construídos a partir dos subtemas Gênero, Direitos Humanos e Saúde. A partir da observação da necessidade de jogos sobre esta temática em plataformas móveis, bem como a necessidade de disseminação do tema para o público geral, foi proposto o processo de redesign do jogo. Assim, o objetivo deste trabalho é descrever como ocorreu este processo de redesign, apresentando resultados de uma avaliação preliminar realizada. Metodologia. O processo de redesign ocorreu em três etapas: construção, adequação da base de conhecimento e testes. Para a primeira etapa foi utilizada a game engine Defold junto com a linguagem de programação LUA para a programação do jogo e sua inteligência. Nessa fase foi possível criar um sistema dinâmico de apresentação das alternativas de resposta, além da utilização de pacotes de edição de imagens, texto e áudio. Na segunda etapa, visando ampliar o público alvo do jogo, toda a base conhecimento passou por um processo de revisão do conteúdo, de modo que a terminologia e a forma de abordagem dos conceitos foram adequadas. Finalmente, na terceira etapa, o jogo foi disponibilizado para testes em um grupo restrito de 30 alunos de graduação e pós-graduação de duas instituições de ensino superior. Os alunos foram instruídos a instalar o jogo em seus dispositivos móveis, jogá-lo e, posteriormente responder a um questionário sobre satisfação [3][4]. Resultados. O novo jogo (Figura 1) foi disponibilizado na plataforma GooglePlay e, a partir da análise das respostas dos questionários, foi possível verificar que os usuários sentiram-se satisfeitos em todas as dimensões avaliadas. Porém, dentre os resultados obtidos, a dimensão da "Imersão" chamou a atenção por evidenciar a satisfação apenas com a imersão emocional, e não com a imersão física. Discussão. Os resultados obtidos permitiram observar que os objetivos foram alcançados, bem como despertar a possibilidade de utilização de novas tecnologias que permitam alcançar a imersão física dos usuários. O jogo está disponível em https://play.google.com/store/apps/details?id=br.ufpb.labteve.caixapandora.
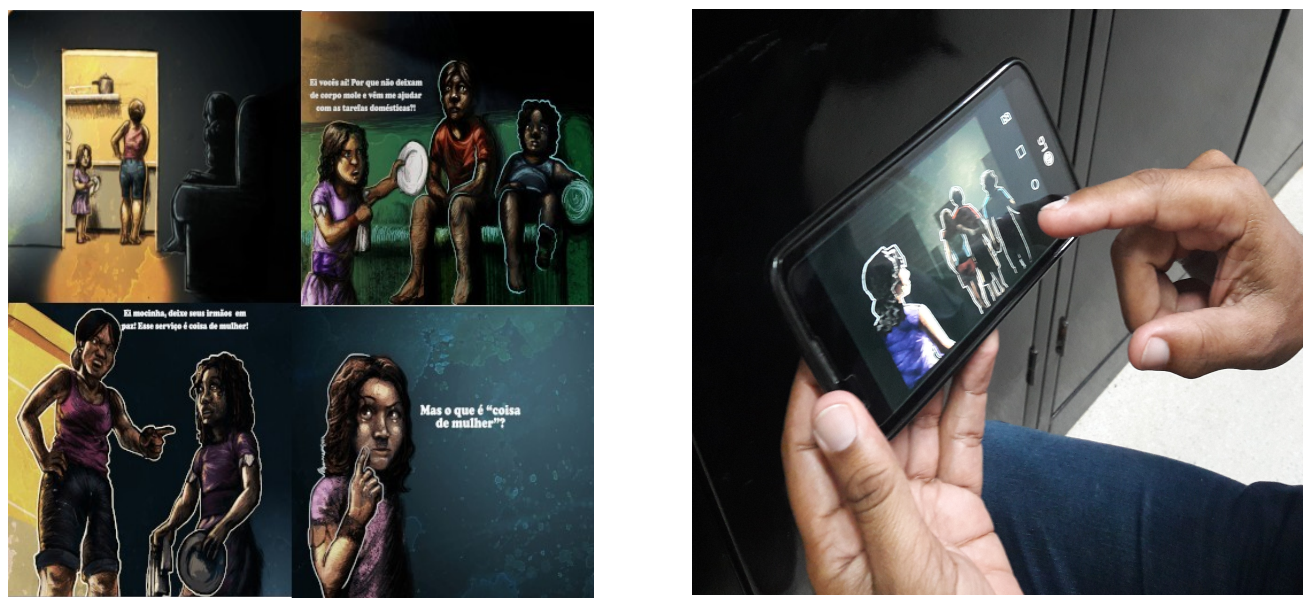

Figura 1. Imagem dos passatempos e execução no dispositivo móvel.

\section{Bibliografia}

[1] Machado, L. S. et al . (2011) Serious games baseados em realidade virtual para educação médica. Rev. Bras. Educ. Med. 35(2): 254-262. DOI: $10.1590 / S 0100-55022011000200015$

[2] Almeida, L.R.; Machado, L.S.; Medeiros, A.T. et al. (2018) The Caixa de Pandora game: changing behaviors and attitudes towards violence against women. ACM Computers in Entertainment 16(3). DOI: 10.1145/3236493

[3] Sweetser, P.; Wyeth, P. (2005) GameFlow: a model for evaluating player enjoyment in games. Computers in Entertainment (CIE) 3(3). DOI: $10.1145 / 1077246.1077253$

[4] Rigby, S.; Ryan, R. (2007) The player experience of need satisfaction (PENS) model. Immersyve Inc, 22p. Online: http://immersyve.com/white-paper-the-player-experience-of-need-satisfaction-pens-2007/\# 